Farm animal welfare - who writes the rules?

Occasional Publication No. 23 - British Society of Animal Science 1999

edited by A. J. F. Russel, C. A. Morgan, C. J. Savory, M. C. Appleby and T. L. J. Lawrence

\title{
Evaluation of training, certification and career development strategies for livestock industry workers in Scotland, Greece, Spain, Italy and Norway
}

\author{
P. R. English1, O. McPherson', S. G. Deligeorgis ${ }^{2}$, J. M. Vidal ${ }^{3}$, C. Tarocco 4 , F. Bertaccini ${ }^{4}$ \\ and $\mathrm{H}$. Sterten ${ }^{5}$ \\ ${ }^{1}$ Department of Agriculture, University of Aberdeen, MacRobert Building, 581 King Street, Aberdeen AB24 $5 U A$ \\ ${ }^{2}$ Agricultural University of Athens, Greece \\ Inatega SA, Leon, Spain \\ ${ }^{4}$ University of Bologna, Italy \\ ${ }^{5}$ Felleskjopet Forutvikling, Trondheim, Norway
}

\section{Introduction}

The studies of Seabrook (1974 and 1984) with dairy cows and Hemsworth et al. (1981 and 1986) and Ravel et al. (1996 and 1999) with pigs, demonstrated significant influences of the stockperson on animal performance and indices of welfare. Despite this important influence in the livestock industries, comparatively little research has been carried out to establish the scientific basis of stockmanship so that the components of this resource could be measured and improved (English et al., 1992; Hemsworth and Coleman, 1998).

English et al. (1992), Erven (1992) and Hemsworth and Coleman (1998) have drawn attention to the complexity of livestock care jobs, since they demand a comprehensive understanding of the needs of the animals and a high level of skills in providing for these needs and in handling the animals generally. This emphasizes the need for suitable education and training. In addition, other livestock industry researchers have drawn attention to the needs of workers in any job for motivation, job satisfaction and good team spirit/team working in any management-employee group (Maslow, 1954; Bowen, 1992; Grusenmeyer, 1992; Umphrey, 1992). The well established principle of regular and progressive training as motivating influences contributing to job satisfaction and job performance in non-agricultural industries has been emphasized (Lloyd, 1975; English et al., 1992). Other positive influences on motivation, job satisfaction and job performance established in the livestock industries include a progressive career structure (Erven, 1992; Umphrey, 1992), status enhancing job titles (Bray, 1992; Umphrey, 1992), and team working including a sense of partnership in the business with an influence on 'trouble shooting', working out solutions, setting targets and policy making in general (Bowen, 1992; Grusenmeyer, 1992).

Therefore, the theoretical ingredients of high quality stockmanship including careful selection of employees, ensuring good working conditions, regular and progressive provision of relevant education and training, a dynamic career structure to recognize achievements, team working, motivation and job satisfaction, appear to be well established. However, the available evidence indicates that stockpeople in general are not well provided for in terms of essential provisions which would help them to be more competent in, and satisfied with, their work and also to make a much larger contribution to the care of their animals, animal welfare and productivity, the efficiency of the livestock enterprise and the success of the business.

One syndrome of this general lack of provision for stockpeople is high job turn-over in the livestock industries (Segundo, 1989; Cleary, 1990; Goodman, 1990; English et al., 1992; Howard et al., 1996) Hemsworth and Coleman, 1998). A job turn-over rate varying from 2 to 5 years has been reported in these studies. Howard et al. (1990) described job turn-over as 'a disruptive, costly process' on the running of the enterprise, especially in relation to team working. The main causes of job dissatisfaction leading to employee turn-over have been found to be autocratic management style, poor communication opportunities with management, sub-optimal provisions for animal care and the lack of both training provisions and recognition of achievements (Segundo, 1989; Howard et al., 1990). The great majority of studies have shown that pay rewards appear to be acceptable. In this latter context, Howard et al. (1990), in their studies in Canada, have 
drawn attention to the fact that pay scales in the agricultural sector in general are considerably below those in other equivalent industry sectors. They allude to the non-pay attractions of working in the agricultural sector. Therefore, it would appear that the high turn-over of staff in the livestock sector could be reduced if more attention was paid to nonpay related provisions which are important to stockpeople. Therefore, in the present study, the provision of on-farm education and training, the concept of a dynamic career structure, recognition of achievements by way of certification and the attitude of stockpeople to status-enhancing job titles, were evaluated.

\section{Material and methods \\ Training materials}

Educational and training materials were developed which were designed to meet the training needs of the stockpeople and management staff in different livestock industry sectors: pigs; dairy cows and calves; milk sheep and lambs. These materials took the form of educational training manuals, slide sets, videos, skills exercise, knowledge tests and questionnaires to evaluate the courses and the other initiatives.

\section{Training approaches}

An on-farm training approach was adopted so that the entire working team - owner, managers and stockpeople could be together for training. The owner and/or the manager of the farm was approached with regard to their willingness to participate and the number of farm staff attending each course varied from four to 20 . The timing of training was selected to suit the farm staff, the least busy day of the week for the staff being selected. The preferred course timings in the dairy and pig sectors were 9.00 to $11.30 \mathrm{~h}$ and 13.00 to $17.00 \mathrm{~h}$ respectively. Before the course, the livestock enterprise was inspected by the trainers along with the owner and/ or the manager, to see the stockpeople at their work and to assess the strengths and weaknesses of the system and the specific problem areas which should be a particular focus for education, training and discussion within the training group. The training took place either in the farm office on in a room in the farm house.

\section{Course procedure}

The course was initiated by the introduction of all participants to each other in an attempt to form an atmosphere conducive to good team-working. The objectives of the project were outlined and particularly the rôle of the course tests. Since the aims of these tests could be misinterpreted and be intimidating to some participants, it was explained that the 'knowledge tests' before and after the course were designed to evaluate the course content and the delivery and not to test individual participants. Thereafter, the pre-course test was conducted and this involved approximately 20 short answer 'truefalse' or 'tick the correct answer' type of questions. The course then proceeded with slide and video presentations and skills exercises (e.g. piglet fostering practices) conducted using paper exercises. In these presentations, particular focus was placed on principles and practices pertaining to problem areas on the farm. Full opportunity was afforded for intervening discussion, for clarifying misunderstandings, focusing on problem areas and working out the best and most cost-effective solutions. At the completion of this session, the post course test was conducted. Thereafter, all course participants completed a 'course evaluation form' in which they were asked to evaluate all aspects of the course. In addition, they were asked to indicate their desire for regular training and desired frequency of training. Their opinions were also sought on a dynamic career structure and, if they favoured such, they were asked to state their main reasons for such interest. They were also asked to examine a list of alternative job titles and to select the title which most appealed to them. Finally, they were asked to answer questions on their career aspirations.

At the end of the course, all participants were given a copy of the training manual which had been produced as part of the project and invited to study it prior to the next training session. They were also invited to borrow video material, when available, so as to provide the opportunity for self-learning. Finally, course certificates were presented to each participant, the grading being decided in advance by the owner and/or the manager to reflect the competence in the workplace of each employee.

Following the completion of the course, a 'consultancy report to management' was produced. This report was based on (a) observations made of strengths and weaknesses during the pre-course visit to the livestock enterprise, (b) the farm records to date and (c) the comments/suggestions of the owner (and manager) and also those of the stockpeople made during the course. This report was designed to guide farm policy in the subsequent months before the next training course/"policy formulation exercise'.

All courses conducted in Scotland and Italy in both the pig and dairy sectors were conducted on farm. All courses conducted in Spain, Greece and Norway in the pig, sheep milk and lamb sectors involved small family farms and were conducted on a group basis at a central location. 
Table 1 Responses to post-course questionnaires

\begin{tabular}{|c|c|c|c|c|c|c|c|c|c|}
\hline \multirow[b]{3}{*}{ Sector } & \multirow{2}{*}{$\begin{array}{c}\begin{array}{c}\text { Degree of satisfaction } \\
\text { with course materials } \\
\text { and course delivery }\end{array} \\
\begin{array}{c}\text { Classification of very } \\
\text { useful/usefult }\end{array}\end{array}$} & \multirow{2}{*}{$\begin{array}{l}\text { Acceptability of } \\
\text { course duration } \\
\text { of } 2 \text { to } 5 \mathrm{~h}\end{array}$} & \multicolumn{3}{|c|}{$\begin{array}{l}\text { Optimum } \\
\text { course } \\
\text { length }(h)\end{array}$} & \multicolumn{4}{|c|}{$\begin{array}{c}\text { Desired course } \\
\text { frequency } \\
\text { (months) }\end{array}$} \\
\hline & & & 2 & 3 & 4 & 1 & 2 & 6 & 12 \\
\hline & $\%$ participants & $\%$ participants & \multicolumn{3}{|c|}{$\%$ participants } & \multicolumn{4}{|c|}{$\%$ participants } \\
\hline Pig & $98 \cdot 8$ & $94 \cdot 9$ & 25 & 44 & 31 & 24 & 35 & 35 & 6 \\
\hline Dairy & $94 \cdot 3$ & 88.9 & 26 & 55 & 19 & 22 & 33 & 37 & 7 \\
\hline Sheep & $92 \cdot 1$ & $76 \cdot 3$ & 37 & 29 & 34 & 42 & 36 & 15 & 7 \\
\hline
\end{tabular}

+ Relative to 'moderately useful/ waste of time'.

\section{Results}

A total of 111 'test courses' $(56,23$ and 32 in the pig, dairy and sheep milk and lamb sectors respectively), involving 1386 participants and 7289 person training hours were conducted and evaluated. Of these courses, 47, 21, 23, 9 and 11 were conducted in Scotland, Spain, Greece, Italy and Norway respectively. In Scotland and Italy there was universal support for on-farm training in the pig and dairy sectors as it could be 'purpose built' to the specific needs of each farm. The results of the course evaluations and responses to related questions regarding the preferred duration and frequency of courses are summarized in Table 1.

Thus, a very high proportion of course participants (92.1 to $98.8 \%$ ) found the courses, the course materials and delivery methods to be 'very useful/

Table 2 Pre-and post-course test scores

\begin{tabular}{|c|c|c|c|c|}
\hline \multirow[b]{2}{*}{ Country } & \multirow{2}{*}{$\begin{array}{l}\text { No. of } \\
\text { courses }\end{array}$} & \multicolumn{2}{|c|}{ Test scores } & \multirow{2}{*}{$\begin{array}{c}\text { Increase } \\
\%\end{array}$} \\
\hline & & Pre & Post & \\
\hline \multicolumn{5}{|c|}{ A. Pig Sector } \\
\hline Scotland & 26 & $71 \cdot 9$ & $82 \cdot 0$ & $14 \cdot 0$ \\
\hline Spain & 5 & $60 \cdot 8$ & $80 \cdot 8$ & $32 \cdot 9$ \\
\hline Italy & 7 & $60 \cdot 2$ & $77 \cdot 4$ & $28 \cdot 6$ \\
\hline Greece & 3 & $59 \cdot 0$ & $89 \cdot 0$ & $50 \cdot 8$ \\
\hline Weighted & ean & $67 \cdot 6$ & $81 \cdot 6$ & $20 \cdot 7$ \\
\hline \multicolumn{5}{|c|}{$\begin{array}{l}\text { B. Dairy cow and } \\
\text { calf sector }\end{array}$} \\
\hline Scotland & 19 & $88 \cdot 0$ & 94.5 & $7 \cdot 4$ \\
\hline Spain & 4 & $53 \cdot 0$ & $67 \cdot 0$ & $26 \cdot 4$ \\
\hline Weightec & & $81 \cdot 9$ & $89 \cdot 7$ & 9.5 \\
\hline \multicolumn{5}{|c|}{$\begin{array}{l}\text { C. Sheep milk and } \\
\text { lamb sector }\end{array}$} \\
\hline Spain & 6 & $54 \cdot 5$ & $58 \cdot 7$ & $7 \cdot 7$ \\
\hline Greece & 6 & $51 \cdot 8$ & 74.8 & $44 \cdot 4$ \\
\hline Mean & & $53 \cdot 2$ & $66 \cdot 7$ & $25 \cdot 4$ \\
\hline
\end{tabular}

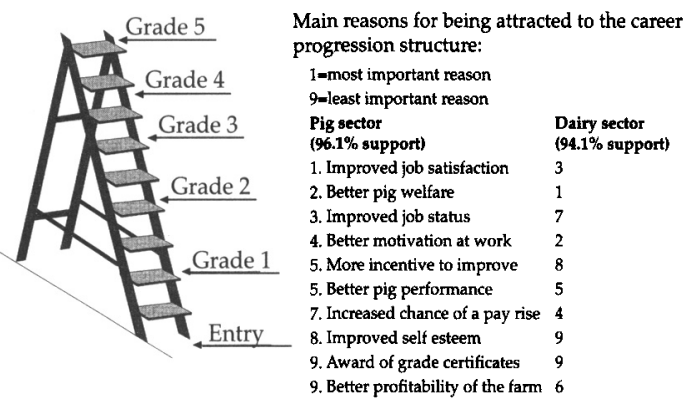

Figure 1 Concept of a career progression ladder.

useful'. The preferred duration of individual courses varied between 2 and $4 \mathrm{~h}$ with most support for 3-h courses and almost as much support for 4-h as for 2-h courses. Participants expressed a strong wish for very regular training - at 6-monthly intervals or even more frequently in the majority of cases.

The results of pre- and post-course knowledge tests are presented in Table 2 . The post-course test scores were $20.7,9.5$ and $25.4 \%$ higher than the pre-course test scores in the pig, dairy and sheep sectors respectively.

In the pig and dairy sectors, respectively, 96.1 and $94.1 \%$ of course participants were attracted to the idea of a career progression structure, going from basic entry grade through grades 1 to 5 . (see Figure 1).

The main reasons for being attracted to such a career progression structure in the pig sector were (in order of priority): (1) improved job satisfaction; (2) the attainment of better pig welfare; (3) improved job status; (4) better motivation at work; (5) greater incentive to improve. 'Increased chance of a pay rise' 
came well down the priorities in the reasons for being attracted to the structure, which surprised many employers and managers. It appeared that many employers did not understand the aspirations of their employees. In the dairy sector, the main reasons for being attracted to such a career ladder were: (1) the attainment of better animal welfare; (2) better motivation at work; (3) improved job satisfaction and (4) increased chance of a pay rise.

\section{Alternative job titles}

Course participants were provided with a list of alternative job titles and asked to select the one which they preferred. The job titles incorporated a list of component terms in the pig sector such as pig, animal, livestock, stock (as in 'stockman'), care or carer and technician or specialist, and equivalent terms in the dairy sector. In the list of job titles in the pig and dairy sectors there were as many titles incorporating general terms such as 'animal', 'livestock', and 'stock' as there were specific 'pig' or 'cow'/'dairy' terms in the choices provided. The breakdown of preferred components of a job title for 70 pig and 17 dairy stockpeople are summarised in Table 3

Table 3 Preferred component terms in job title

\begin{tabular}{|c|c|c|c|c|}
\hline Pig sector & Pig & $\begin{array}{c}\text { Animal/Stock } \\
\text { /Livestock }\end{array}$ & $\begin{array}{l}\text { Technician } \\
\text { Specialist }\end{array}$ & $\begin{array}{l}\text { Care } \\
\text { Carer }\end{array}$ \\
\hline \multicolumn{5}{|c|}{ Stockpeople } \\
\hline No. & 30 & 40 & 43 & 28 \\
\hline$\%$ & $42 \cdot 9$ & $57 \cdot 1$ & $61 \cdot 4$ & $40 \cdot 0$ \\
\hline & low / Catt & e Animal/Stock & Technician & Care \\
\hline Dairy secto & /Dairy & / Livestock & Specialist & Carer \\
\hline \multicolumn{5}{|c|}{ Stockpeople } \\
\hline No. & 3 & 14 & 10 & 10 \\
\hline$\%$ & $17 \cdot 6$ & $82 \cdot 4$ & 58.8 & $58 \cdot 8$ \\
\hline
\end{tabular}

Thus, in the pig sector, a majority of stockpeople $(57.1 \%)$ expressed a preference not to have the prefix 'pig' in their job title. Sixty-one per cent were attracted to the terms 'technician' or 'specialist' in their job title and $40 \%$ to the terms 'care' or 'carer'. Dairy stockpeople provided similar responses. If the title of the pig and dairy stockpeople was changed to 'animal care specialist', 93.2 and $76.5 \%$ in the pig and dairy sectors respectively indicated that they would support such a change.

\section{Discussion}

The results provide considerable encouragement that with (1) the provision of training packages carefully designed in relation to educational/training needs and appropriate delivery methods, (2) regular and progressive training, (3) additional motivational influences such as a career ladder and (4) selection of more descriptive and status-enhancing job titles, livestock industry posts would become more attractive to personnel already in post and also to potential recruits to the livestock care profession. Some of these aspects will be discussed in turn.

\section{Alternative education/training provisions and their impact}

Existing training provisions for stockpeople include instruction from the owner, manager or senior stockpeople, vocational training at colleges, training agency courses on specific skills and techniques, and lectures on technical topics organized by ancillary industry sectors such as animal food and breeding companies or veterinary groups. While these provisions all play an important rôle in the education and training of farm staff, it is not usually possible for more than a small proportion of employees to attend outside training courses and lectures. In addition, these alternative training provisions do not constitute a specifically designed 'package' to meet the specific training needs of each farm, in which the entire farm team can participate. In a survey in Scotland carried out by Wright (1985) on alternative training provisions, a clear preference was expressed by stockpeople for on-farm training. In addition, Grusenmeyer (1992) has emphasized the importance of the team-building, motivational and job satisfaction aspects of on-farm training in which the owner, manager and all staff are involved. Grusenmeyer (1992) also referred to the excellent opportunity provided by 'on-farm' training for the entire team to be involved together in trouble shooting, the identification and solution of problems and for policy formation. Good stockpeople value the opportunity to become involved in such problem solving and forward planning. This provides them with a greater sense of belonging and partnership in the business. Such involvement has been demonstrated to be a strong motivator of staff and to contribute substantially to job satisfaction (Bowen, 1992).

The involvement of the owner and manager with staff in regular training sessions, in which problems of livestock care and productivity are addressed and solutions worked out together, would be likely to remove most of the causes of job dissatisfaction found by Segundo (1989) in pig herds in Scotland. Many of these related to poor communication and inadequate time for discussion on livestock related problems between management and stockpeople. 
Attitude of stockpeople to training

What was extremely encouraging in the current project was the very positive attitude of stockpeople to training, the concentration and interest which they demonstrated, their enthusiastic participation in discussion and their desire to address and solve problem areas in the enterprise. As indicated earlier, they expressed a wish to have regular training of this nature (at 2 to 6 monthly intervals) and for training sessions to last for an average of $3 \mathrm{~h}$ with more than $25 \%$ of stockpeople expressing a wish for continuous 4-h training sessions fitted into a normal working day! This is indicative of a craving for education and training along with the associated discussion, troubleshooting and problem solving elements.

In conducting the training, many training sessions in the pig sector did last for a continuous period of $4 \mathrm{~h}$ usually from 13.00 to $17.00 \mathrm{~h}$, with only a very short half-time break for refreshments. When these training sessions had been completed and as the 'trainers' were preparing to leave, the stockpeople sought to ask further questions and to continue the discussion. This was despite the fact that they had their animal care work to complete for the day and none of the stockpeople involved sought extra overtime payments for their prolonged day. This reflects their great thirst for learning and training and their attitude towards understanding their animals and to caring for them more effectively.

\section{Career structures and certification}

Regarding the concept of a dynamic career structure, this was accorded a very high level of support (96.1 and $94.1 \%$ in the pig and dairy sectors respectively). The main reasons for their interest in such a career ladder related to improved job status and selfesteem, greater motivation to improve their understanding and animal care (welfare) and better job satisfaction. Their linking of career ladder advancement with increased pay came well down the list of their priorities for being attracted to such a career structure. These responses surprised many owners and managers who anticipated that the linking of advancement up the career ladder to pay would be at the top of the priorities for their stockpeople. This is a common misconception among industry leaders, for in most studies on the job satisfaction/dissatisfaction of livestock industry employees, many non-pay factors feature much more highly in causes of dissatisfaction than does low pay (Segundo, 1989; Grusenmeyer, 1992).

The apparent indifference of stock people to the award of a grade certificate was surprising. This may reflect the fact that material things such as pay and certificates were less important to them than non material factors such as self-esteem. It must be pointed out that stockpeople had completed their questionnaires before they were awarded with their 'animal care specialist' grade certificate. On further reflection, perhaps influenced by their family's responses, they may value their attainment certificate more highly.

Alternative job titles and the profession of animal care Regarding job titles, it is important to most people that the title of the job they do reflects the standing and nature of the job as well as the knowledge and skills required. Job titles such as 'pigman' or 'cowman' for very knowledgeable, high skilled and caring stockpeople do not give any impression of such qualities. A marked preference was expressed in both the pig and dairy sectors for 'non-pig' and 'non-cow/non-dairy' job title components to be replaced by more general 'animal/stock/livestock' prefixes. Strong support was also expressed for the inclusion of the terms specialist or technician and care or carer in the job title. The preferred title of the authors to reflect the knowledge, skills and animal caring attitude of good stockpeople was 'animal care specialist'. If their current job title was changed to this, a high proportion of the stockpeople (93.2 and $76.5 \%$ in the pig and dairy sectors respectively) indicated their support for such a change. Bray (1992), in the USA dairy sector, has also placed emphasis on the importance of job titles in relation to the image of the job and the self esteem and status of good stockpeople. Bray (1992) claimed that a more worthy job title in keeping with the knowledge, skills and animal caring attitude of the employee was an important factor which increased the chances of obtaining, for example, a bank loan and credit facilities.

English et al. (1992) and Hemsworth and Coleman (1998) have emphasized the importance of recognizing livestock care as a profession in relation to the self esteem of good stockpeople already in post and the attractiveness of the job to prospective employees. It would seam logical that there should be one general title for all livestock carers rather than a range of titles according to the species concerned. Bray (1992) has referred to the challenge of obtaining a bank loan or credit facilities in a store with some current job titles. Because of the distorted attitude of some sectors of society to those who care for animals as a 'cowman' or 'pigman' or a 'henwife', stockpeople will almost certainly have higher status in the eyes of others and may perhaps also be more credit worthy if they are a member of the very worthy profession of 'animal care specialists'.

\section{Aspirations of the stockpeople}

The pig stockpeople participants in the current study were asked about their future job aspirations if a 
dynamic career structure was in place. Over $90 \%$ wished to remain in the pig industry as a career, and all aspired to move progressively up the career ladder. Half of these aimed to progress into section or unit management, while the other half wished to remain as a stockperson and to become progressively more knowledgeable, skilled and competent in the workplace. This was a very encouraging commitment to the pig industry.

This constituted the last question in the questionnaire. Prior questions covered their evaluation of the course and course materials, their desire for regular and progressive 'on-farm' training, the duration and frequency of such training, their attitude to a dynamic career structure and to statusenhancing job titles. It is possible that the answers regarding job aspirations were influenced by their vision of better times ahead involving regular training, an exciting career structure, better selfesteem and status, team working, greater sense of partnership in the business and generally better motivation and job satisfaction.

These possible effects of the initiatives, as well as the job turn-over rate, the attractiveness of the job to new applicants, the number of applicants for jobs, the quality of animal care, animal performance, enterprise efficiency and business success, have yet to be evaluated.

\section{Acknowledgements}

We are grateful to the European Union for the award of a grant for this work under the Leonardo da Vinci programme.

\section{References}

Bowen, M. K. 1992. The role of the dairy manager in human resource management. In Large dairy herd management (ed. H. H. Van Horn and C. J. Wilcox), pp. 757-763. American Dairy Science Association.

Bray, D. R. 1992. Job descriptions and job images. In Large dairy herd management (ed. $\mathrm{H}$. $\mathrm{H}$. Van Horn and $\mathrm{C}$. J. Wilcox), pp. 772-776. American Dairy Science Association.

Cleary, G. V. 1990 . Personnel management and record keeping. In Pig production in Australia (ed. J. A. A. Gardner, A. C. Dunkin, and L. C. Lloyd), pp. 284-291. Australian Pig Research Council, Canberra. Butterworths.

English, P. R., Burgess, G., Segundo, R. and Dunne, J. H. 1992. Stockmanship: improving the care of the pig and other livestock. Farming Press, Ipswich, Suffolk, England.

Erven, B. L. 1992. Recruiting, selecting and training dairy farm employees. In Large dairy herd management (ed. $\mathrm{H}$. $\mathrm{H}$.
Van Horn and C. J. Wilcox), pp. 777-785. American Dairy Science Association.

Goodman, S. 1990. Effective staff management. In Proceedings of Conference and Trade Fair 'Pigs North East', York Racecourse. (MLC/ADAS/NFU/Farmers Guardian) March 1990. Meat and Livestock Commission, Milton Keynes.

Grusenmeyer, D. 1992. Maximising human resource output. In Large dairy herd management (ed. H. H. Van Horn and C. J. Wilcox), pp. 764-770. American Dairy Science Association.

Hemsworth, P. H., Barnett, J. L. and Hansen, C. 1981. The influence of handling by humans on the behaviour, growth and corticosteroids in the juvenile female pig. Hormones and Behaviour 15: 396-403.

Hemsworth, P. H., Barnett, J. L. and Hansen, C. 1986. The influence of handling by humans on the behaviour, reproduction and corticosteriods of male and female pigs. Applied Animal Behavioural Science 15: 303-314.

Hemsworth, P. H. and Coleman, G. J. 1998. Human livestock interactions: the stockperson and the productivity and welfare of intensively farmed animals. CAB International, Wallingford.

Howard, W. H., McEwan, K. A., Brinkman, G. L. and Christenson, J. 1990. Human resource management on the farm: attracting, keeping and motivating labour on Ontario swine farms. Department of Agricultural Economics and Business, University of Guelph, Guelph, Ontario, Canada.

Lloyd, D. H. 1975. Effective staff management. In Economic factors affecting egg production. (ed. B. M. Freeman and K. N. Boorman), pp. 221-231. British Poultry Science, Edinburgh.

Maslow, A. M. 1954. Motivation and personality. Harper \& Brothers, New York.

Ravel, A., D'Allaire, S. and Bigras-Poulin, M. 1996. Survey of management and housing in farrowing quarters among independent and integrated swine farms in Québec. Canadian Journal of Veterinary Research 60: 21-28.

Ravel, A., D'Allaire, S., Bigras-Poulin, M. and Ward, R. 1999. Psychodemographic profile of stockpeople working on independent and integrated swine breeding farms in Québec. Canadian Journal of Veterinary Research In press.

Seabrook, M. 1974. A study of some elements of the cowman's skills as influencing the milk yield of dairy cows. Ph.D. thesis, University of Reading.

Seabrook, M. F. 1984 . The psychological interaction between the stockman and his animals and its influence on performance of pigs and dairy cows. Veterinary Record 115: 84-87.

Segundo, R. C. 1989. A study of stockpeople and managers in the pig industry with special emphasis on the factors affecting their job satisfaction. M.Sc. thesis, University of Aberdeen, Aberdeen.

Umphrey, J. E. 1992. Understanding employee motivation. In Large dairy herd management (ed. H. H. Van Horn and C. J. Wilcox), pp. 786-792. American Dairy Science Association.

Wright, D. 1985. Training investigation: pig production in Scotland. Agricultural Training Board, West Wickham, Kent. 